\title{
MODELOS DE AVALIAÇÃO DA QUALIDADE NO CONTEXTO DA EDUCAÇÃO INFANTIL DE FLORIANÓPOLIS/SC
}

\author{
http://dx.doi.org/10.5902/2318133841363
}

\author{
Dirce Guerres Zucco ${ }^{1}$ \\ Andreia Zanella ${ }^{2}$ \\ Patrícia de Sá Freire ${ }^{3}$
}

\begin{abstract}
Resumo
Neste artigo aborda-se os modelos de avaliação da qualidade da educação infantil e se define os critérios para comparação dos mesmos. Por meio de uma pesquisa qualitativa discute-se e compara-se os modelos aplicados na rede municipal de Florianópolis/SC. Concluiu-se que a avaliação deve considerar diversidade identitária das instituições e as especificidades da educação infantil; bem como precisa ter natureza científica, rigor técnico e procedimentos legitimados de mapeamento. Além da coleta e análise de dados, o resultado da avaliação deve compilar informações do censo escolar e programas de financiamento educacional que fomentam acesso, infraestrutura, recursos materiais, formação de professores e gestão dos sistemas e das instituições.

Palavras-chave: avaliação da qualidade; modelos de avaliação; educação infantil.
\end{abstract}

\section{QUALITY ASSESSMENT MODELS OF EARLY CHILDHOOD EDUCATION IN FLORIANÓPOLIS/SC}

\begin{abstract}
This paper discusses the models used in the assessment of quality of early childhood education and defines comparison criteria. Through a qualitative research, it discusses and compares the models applied in Florianópolis/SC' municipal education system. The research concludes that the evaluation must consider the identity diversity of institutions and the specificities of early childhood education. It must have a scientific nature, technical rigor and legitimate mapping procedures. The results of the evaluation should compile information from the school census and educational funding programs that foster access, infrastructure, material resources, teacher training, and the management of the educational system and institutions.

Key-words: quality assessment; evaluation models; early childhood education.
\end{abstract}

\footnotetext{
${ }^{1}$ Universidade Federal de Santa Catarina, Brasil. E-mail: dirce.guerres@prof.pmf.sc.gov.br.

2 Universidade Federal de Santa Catarina, Brasil. E-mail: andreia.zanella@ufsc.br.

3 Universidade Federal de Santa Catarina, Brasil. E-mail: patricia.sa.freire@ufsc.br.

Regae: Rev. Gest. Aval. Educ. $\quad$ Santa Maria v. 9 n. 18 Pub. contínua 2020 p. $1-17$
} 


\section{Introdução}

tualmente, no Brasil, encontra-se em processo de implantação a avaliação da
qualidade da educação infantil, que compreende a faixa etária de zero a cinco
anos. Essa estratégia de avaliar a qualidade teve início com a Constituição Federal de 1988, que definiu diretrizes para a gestão dos sistemas de ensino. Aos municípios cabe a responsabilidade de ofertar, prioritariamente, a educação infantil e o ensino fundamental em regime de colaboração com os Estados, Distrito Federal e a União. Cabe a União a responsabilidade de coordenar a política nacional da educação, na função normativa, redistributiva e supletiva, por meio de assistência técnica e financeira em regime de colaboração.

No desdobramento da Constituição Federal foi aprovada a Lei de Diretrizes e Bases da Educação, que normatiza o ensino brasileiro e também regulamenta o Plano Nacional de Educação, inicialmente referido no art. 214 da Constituição Federal de 1988.

No escopo de atribuições do PNE está a de prever o financiamento e definir metas e estratégias para a política nacional a serem alcançadas a partir das diretrizes educacionais. Já na sua primeira edição - 2001-2010 - pelo Plano estabeleceram-se regras sobre o financiamento da educação infantil. Na sua segunda edição, promulgada pela lei $n$. 13.005/14, pelo plano se demarcou a realização periódica da avaliação da educação infantil a cada dois anos, a fim de medir a qualidade dos serviços oferecidos pelas instituições e direcionamento das políticas públicas para a primeira etapa da educação básica. A aprovação do PNE insere-se num período de disputas e tensão política sobre o destino dos recursos do produto interno bruto que financia os sistemas de ensino. Coincidentemente também aconteceu o debate sobre as diretrizes da avaliação da qualidade da educação infantil.

Com a descentralização da oferta da educação infantil para os municípios, as leis e diretrizes permaneceram sendo regulamentadas pela esfera federal. Os municípios têm a autonomia e a responsabilidade de prever e a gestar as demandas da primeira etapa da educação básica nas suas respectivas redes de ensino. Por este motivo a educação infantil não foi incluída ao Sistema de Avaliação da Educação Básica - Saeb - ${ }^{4}$, ou seja, ficou à margem do planejamento desta avaliação.

$\mathrm{Na}$ última década o instrumento avaliativo elaborado no Brasil que previa uma autoavaliação institucional por adesão das unidades educativas foi publicado pelo Ministério da Educação em 2009 e intitulado Indicadores da qualidade da educação infantil.

Por não haver uma diretriz nacional de obrigatoriedade, parte dos municípios não realizaram a avaliação da qualidade da educação infantil, enquanto outros que a realizaram disseminaram diferentes tipos e modelos avaliativos. Na maioria das vezes os modelos de avaliação são provenientes de outros países, adaptados ou não ao contexto. Os estudos de Pimenta (2017) e Sousa e Pimenta (2018) abordam as estratégias

${ }^{4}$ O Saeb é composto por um conjunto de avaliações externas em larga escala que permite ao Inep realizar um diagnóstico da qualidade do ensino fundamental e médio em âmbito nacional as redes municipais e estaduais de ensino. O resultado da avaliação é um indicativo da qualidade do ensino brasileiro e oferece subsídios para a elaboração, o monitoramento e o aprimoramento de políticas educacionais com base em evidências. O Saeb tem previsto a inclusão da educação infantil a partir de 2019 como um projeto piloto e, devido as especificidades da educação infantil, torna-se necessário atentar-se a metodologia e a finalidade avaliativa, conforme será descrito ao longo do artigo.

\begin{tabular}{l|l|l} 
Regae: Rev. Gest. Aval. Educ. & Santa Maria & v. 9
\end{tabular} n. 18

Pub. contínua 2020 p. 1-17 
avaliativas de alguns municípios para aferir o nível de qualidade das redes de ensino. Em alguns casos a escolha do modelo de avaliação está condicionada às políticas governamentais, às pesquisas e ao financiamento.

Em 2011 foi instituído, pela portaria n. 1.147/2011, o grupo de trabalho para subsidiar a elaboração de um sistema nacional de avaliação. O referido grupo elaborou o documento intitulado Educação infantil: subsídios para a construção de uma sistemática de avaliação. A partir do estudo sobre a avaliação da educação infantil a estratégia foi definir os objetivos e os critérios metodológicos em consonância com a legislação educacional e com os parâmetros de qualidade.

Assim, o MEC passou a apoiar iniciativas de pesquisa sobre a avaliação, entre elas, Educação infantil no Brasil: avaliação qualitativa e quantitativa (Campos et. al., 2011) e o projeto Formação em rede na educação infantil: avaliação de contexto (Brasil, 2015). O município de Florianópolis/SC realizou a avaliação da qualidade baseada nos modelos de avaliação norte-americanos Infant Toddler Environment Rating Scale - ITERS-R - Early Childhood Environment Rating Scale - Ecers-R -, ambas na versão revisada, que avaliam espaços e ambientes, e também nos instrumentos italianos baseados na avaliação de contexto, que intitulam-se I Indicatori e Scala della Qualità Educativa del Nido - Squen - e Autovalutazione della Scuola dell'Infanzia - AVSI. Na pesquisa conduzida no presente artigo, de natureza bibliográfica e documental, foram analisados e comparados os dois modelos de avaliação aplicados na rede municipal de ensino de Florianópolis/SC.

A avaliação da educação infantil referente ao modelo norte americano foi aplicada no ano de 2009 e contemplou 147 instituições de educação infantil de seis capitais Belém, Campo Grande, Florianópolis/SC, Fortaleza, Rio de Janeiro, Teresina -, das quais 30 unidades faziam parte da rede Florianópolis/SC, ou seja, foi realizada por amostragem. A avaliação foi desenvolvida em parceria com a Fundação Carlos Chagas, o Ministério da Educação e o Banco Interamericano de Desenvolvimento (Campos et. al., 2011). Os resultados gerais mapeados indicam que

os principais resultados revelaram que: creches e pré-escolas apresentam em média níveis de qualidade insatisfatórios; os níveis de qualidade mais comprometidos se referem às atividades (creche e pré-escola), rotinas de cuidado pessoal (creche) e estrutura do programa (pré-escola); mudanças em determinadas características das instituições poderiam levar à melhoria da qualidade da educação infantil nos municípios investigados. (p. 20)

Já o modelo italiano foi aplicado entre 2013 e 2015 e envolveu quatro capitais sendo avaliadas quatro instituições de cada rede - Belo Horizonte, Curitiba, Florianópolis e Rio de Janeiro. O modelo italiano foi aplicado na perspectiva de um estudo qualitativo e teve como objetivo discutir a potencialidade dos instrumentos italianos e os impactos teóricometodológicos de uma avaliação de natureza reflexiva e participante, característico desta experiência italiana em avaliação de contexto (Souza et. al. 2017). O desafio de uma avaliação de contexto é bastante amplo, pois abrange dimensões relacionais, pedagógicas, políticas, estruturais, conforme será apresentado ao longo do presente artigo.

Em 2015 a capital catarinense realizou novamente a avaliação utilizando o modelo norte americano, mas desta vez a avaliação foi censitária e contou com a participação das 87 unidades que faziam parte da rede municipal de ensino. 
Iniciativas similares foram adotadas pelos municípios com modelos e objetivos distintos como, por exemplo, Ages \& Stages Questionnaires - ASQ - no Rio de Janeiro, realizadas de modo censitário em 2010 e por amostragem em 2015 (Fioravanti-Bastos et. al., 2016). Estas avaliações tiveram como objetivo coletar dados sobre a qualidade e também atender a necessidade de implantação da avaliação da educação infantil estabelecida pelo PNE.

\section{Metodologia}

A metodologia utilizada envolveu pesquisa bibliográfica e documental, de natureza qualitativa. As fontes de informação para a busca sistemática de literatura foram selecionadas na Biblioteca Universitária da UFSC a partir das bases de dados WOS, Eric Proquest, Scopus, Scielo para artigos, periódicos, apresentações de palestras. Já o banco de teses e dissertações foi direcionado a esses dois tipos de publicações. Os idiomas selecionados foram inglês e português. Os descritores basearam-se nos termos constados no título, resumo e palavras chaves: avaliação externa, autoavaliação institucional, avaliação em larga escala, avaliação nacional de educação infantil, Anei, indicadores de qualidade, testes padronizados, AND educação infantil, creche, pré-escola. O período das publicações foi entre 2008-2019, pois foi um período que contempla a intensa disseminação de modelos avaliativos no Brasil e por se tratar de um tema com possíveis mudanças a partir das políticas e da legislação educacional

A pesquisa resultou em 1.251 obras relativas aos termos utilizados nos descritores, destas apenas 16 foram selecionadas por estarem alinhadas com o tema trabalhado nesta pesquisa. Entre as obras selecionadas destaca-se a tese Avaliações municipais da educação infantil: contribuições para a garantia do direito à educação das crianças brasileiras?, de Claudia Oliveira Pimenta. A referida tese contribuiu de maneira significativa ampliando as possibilidades de busca a outras referências e autores que tratam da temática. As publicações da legislação educacional também fizeram parte do rol de referências, ancorando as definições e os elementos norteadores deste estudo, que foram selecionados, analisados e descritos de modo a atender os objetivos da proposta.

\section{Modelos de avaliação da qualidade da educação infantil}

Pimenta (2017) apresenta os instrumentos avaliativos desenvolvidos e aplicados em alguns países. A autora estabelece duas categorias de análise: avaliação da educação infantil com foco no desenvolvimento das crianças e com foco nos ambientes, insumos e processos. Cada modelo foi classificado no quadro 1 de acordo com as categorias supracitadas e suas características são descritas de forma resumida. Além dos instrumentos identificados por Pimenta (2017) foram acrescentados dois modelos avaliativos: Ages \& Stages Questionnaires e Strumento per lo Sviluppo di Processi Riflessive e Indagine valutative nei Nidi da parte dei Gruppi di lavoro educativi - Spring. 
Quadro 1 -

Síntese contextualizando alguns modelos de instrumentos avaliativos nos países.

\begin{tabular}{|l|}
\hline \multicolumn{3}{|c|}{ Com foco no desenvolvimento das } \\
crianças \\
\hline Early Years Foundation Stage \\
(Inglaterra): avalia o desenvolvimento \\
da criança para contribuir no \\
desempenho dos estudantes nas \\
etapas seguintes. A avaliação foca na \\
transição da etapa para que seja \\
processual, sem rupturas (Great \\
Britain; Dcsf (2008); Pimenta (2017, \\
p.143)).
\end{tabular}

Com foco nos ambientes, insumos e processos

NQS - National Quality Standard: sistema de avaliaçãos reformulado, baseou-se no ECCQA, guia nacional do padrão de qualidade da Austrália): o processo de avaliação da qualidade está institucionalizado, com a existência de padrões de qualidade nacionais utilizados para realizar o credenciamento, monitoramento e avaliação dos serviços. Abrange de maneira sistêmica todos os serviços prestados para a infância e o resultado da avaliação é a base para o financiamento da educação infantil e a elaboração de políticas públicas (Guide to the national quality framework. Austrália, NQF: ACECQA (2018), Pimenta (2018), Tayler, (2014)).

COR - Child Observation Record (EUA): Avaliação sistemática, baseada na habilidade das crianças, realizado pelos profissionais que tem relação de proximidade com as elas.

High scope educational research foundation (2003); Pimenta, 2017, p.145-148).
Iters-R Infant Toddler Environment Rating Scale e Ecers-R Early Childhood Environment Rating Scale Revised (EUA): Identificam se os espaços e materiais possibilitam 0 acesso as crianças, se estão em quantidade suficiente, adequada a faixa etária e se as crianças tem a oportunidade de escolhas. Bastante disseminado em vários países, tornou-se base outros instrumentos avaliativos, a partir da adaptação ao contexto. Facilidade na habilitação dos avaliadores externos, baixo custo. No entanto, abre precedentes para exclusão do item pais e equipe, dispensando a participação da equipe e comunidade (versão revisada Harms, Clifford E Cryer (2006), Harms (2013), Pimenta (2017)).

ASQ - Ages \& Stages Questionnaires (EUA e RJ): avalia individualmente o desenvolvimento infantil em cinco domínios: comunicação, coordenação motora ampla e fina, resolução de problemas e a relação pessoal/social Rio de Janeiro, 2010; FioravantiBastos et. al., 2016.
ECCP - Escala de evaluación de la calidad educativa en centros preescolares (México): A avaliação era um dos requisitos para a reformulação do sistema de ensino. Com a expansão da oferta o desafio era levantar os dados por meio de uma avaliação ampla que contemplasse todas as dimensões, na diversidade das instituições e da população. O feedback da avaliação era a base para a continuidade dos currículos que estavam sendo implementados (Myers, 2011; Preciado, 2010).

IDEA - Proposição do Instituto de Evaluación y Asesoramiento Educativo (Espanha): Avaliação é por adesão da instituição. Avalia a estrutura física, currículo, aprendizagem, segurança, saúde. Utiliza questionário direcionado as famílias e a equipe docente. Na Espanha a educação infantil é obrigatória dos 4 aos 6 anos. De 0 a 3 anos apenas 30\% das crianças são atendidas e os profissionais são menos qualificados. (Akvile (2014), Pimenta (2017).

Isquen/AVSI (Itália): Adaptada da Iters-R e Ecers-R ao contexto italiano, apresenta objetivos, metodologia e finalidade distinta. Inclui na definição da metodologia o debate sobre a qualidade negociada. Inclui também a formação dos profissionais ao longo 
\begin{tabular}{|l|l|}
\hline \multicolumn{1}{|l}{} & da avaliação. Demanda maiores investimentos, \\
avaliadores externos e internos, mas possibilita a \\
discussão dos resultados com correção das \\
distorções (Pimenta; 2017, Coutinho et. al. (2015); \\
Bondioli; Sávio, 2014)
\end{tabular}

Fonte: autora.

No Brasil foram selecionados dois instrumentos de avaliação criados para avaliar a instituição: Indicadores da qualidade na educação infantil (MEC, 2009) e Indicadores da qualidade da educação infantil paulistana (2015). Trata-se de uma autoavaliação institucional, ambos pertencentes a categoria de avaliação dos ambientes, insumos e processos. De modo sucinto, e atento aos contextos institucionais, o texto aborda o termo qualidade enquanto pressuposto que depende de muitos fatores: os valores nos quais as pessoas acreditam; as tradições de uma determinada cultura; os conhecimentos científicos sobre como as crianças aprendem e se desenvolvem; o contexto histórico, social e econômico no qual a escola se insere (Brasil, 2009, p. 13). De modo operacional apresenta os critérios de avaliação baseados em sete dimensões subdivido em indicadores, com a participação das equipes de educadores, os pais, as pessoas da comunidade e as autoridades responsáveis, a fim de ajudar a melhorar a qualidade das instituições de educação infantil (Brasil, 2009).

Já o segundo documento foi elaborado com a mesma metodologia do documento publicado pelo MEC, apenas adaptado ao contexto da rede municipal de ensino de São Paulo, acrescendo duas dimensões ao documento original. Os principais detalhes são apresentados no quadro 2.

\section{Quadro 2 -}

Síntese das características dos Indicadores Nacionais e Paulistano.

\begin{tabular}{|c|c|}
\hline $\begin{array}{c}\text { Indicadores da qualidade na educação } \\
\text { infantil (MEC, 2009) }\end{array}$ & $\begin{array}{c}\text { Indicadores de qualidade da educação infantil } \\
\text { paulistana (2015) }\end{array}$ \\
\hline $\begin{array}{l}\text { Abrangência nacional, com critérios para a } \\
\text { autoavaliação participativa da qualidade da } \\
\text { oferta de atendimento as crianças no espaço } \\
\text { coletivo e institucional. Com linguagem } \\
\text { acessível, utiliza cores do semáforo para } \\
\text { coletar os dados e indicar o nível de } \\
\text { qualidade. Apresenta } 7 \text { dimensões: 1- } \\
\text { planejamento institucional; } 2 \text { - multiplicidade } \\
\text { de experiências e linguagens; } 3 \text { - interações; } \\
4 \text { - promoção da saúde; } 5 \text { - espaços, } \\
\text { materiais e mobiliários; } 6 \text { - formação e } \\
\text { condições de trabalho das professoras e } \\
\text { demais profissionais; } 7 \text { - cooperação e troca } \\
\text { com as famílias e participação na rede de } \\
\text { proteção social (Brasil, 2009, p.13). }\end{array}$ & $\begin{array}{l}\text { Reformulado a partir dos Indicadores da } \\
\text { Qualidade na Educação Infantil. Apresenta } \\
\text { metodologia semelhante, acrescentando plano } \\
\text { de ação após os dados coletados e com nove } \\
\text { dimensões, dois a mais do documento base, } \\
\text { adequando-se a proposta pedagógica do } \\
\text { município. Com as seguintes dimensões: } 1 \text { - } \\
\text { Planejamento e gestão educacional; } 2 \text { - } \\
\text { Participação, escuta e autoria de bebês e } \\
\text { crianças; } 3 \text { - Multiplicidade de experiências e } \\
\text { linguagens em contextos lúdicos para as } \\
\text { infâncias; } 4 \text { - Interações; } 5 \text { - Relações étnico- } \\
\text { raciais e de gênero; } 6 \text { - Ambientes educativos: } \\
\text { tempos, espaços e materiais; } 7 \text { - Promoção da } \\
\text { saúde e bem-estar: experiências de ser }\end{array}$ \\
\hline & \\
\hline
\end{tabular}




\begin{tabular}{|l|l|}
\hline & $\begin{array}{l}\text { cuidado, cuidar de si, do outro e do mundo; 8 - } \\
\text { Formação e condições de trabalho das } \\
\text { educadoras e dos Educadores; 9 - Rede de } \\
\text { proteção sociocultural: unidade educacional, } \\
\text { família, comunidade e cidade (São Paulo, 2016, } \\
\text { p. 4) }\end{array}$ \\
\hline
\end{tabular}

Fonte: autora.

O caso paulistano demonstra a possibilidade de adaptação de um instrumento avaliativo, pois contempla as especificidades de sua proposta pedagógica, aproximando ao seu contexto de modo significativo e participativo. No documento se enfatiza que

distinguir entre diferentes dimensões de qualidade não significa considerar que elas sejam desligadas umas das outras, mas ao contrário, implica reconhecer que essas dimensões tocam em aspectos que muitas vezes são comuns. Assim, as dimensões de qualidade procuram iluminar diversos ângulos de um mesmo processo educativo, de forma a viabilizar uma reflexão e discussão coletiva e facilitar a elaboração de um plano de ação que focalize os diferentes problemas que devem ser superados para se obter os ganhos de qualidade desejados. (São Paulo, 2016, p. 9)

Um instrumento avaliativo na educação infantil difere-se de um instrumento utilizado nas outras etapas da educação básica. Além de estar em consonância com o currículo, com as diretrizes e com a Base Nacional Comum Curricular - BNCC -, necessita ser abrangente, a nível de sistema, assegurando a qualidade em relação a oferta, insumos e processos.

Devido a especificidade da educação infantil, não é recomendado que a avaliação da qualidade seja pautada em níveis do desenvolvimento e nem testes de proficiência, pois as infâncias são distintas, não são definidos conteúdos específicos, assim como os ritmos de desenvolvimento infantil não são lineares. Por isso, não se pode ter como referência padrões de competência e comportamento. Segundo Bondioli (2014) "isto se deve a variabilidade nos ritmos de desenvolvimento da criança [...] em que a verificação dos resultados não poderia se configurar como um diagnóstico confiável” (p. 59).

No sentido de contribuir para as iniciativas avaliativas nos municípios brasileiros, no documento intitulado Educação infantil: subsídios para a construção de uma sistemática de avaliação (Brasil, 2012) se esclarece que

a avaliação na educação infantil se refere àquela feita internamente no processo educativo, focada nas crianças enquanto sujeitos e coautoras de seu desenvolvimento. Seu âmbito é o microambiente, o acontecer pedagógico e o efeito que gera sobre as crianças. Ela é feita pela professora, pelas pessoas que interagem com ela no cotidiano e pelas próprias crianças. A avaliação da educação infantil toma esse fenômeno sociocultural [...] visando a responder se e quanto ele atende à sua finalidade, a seus objetivos e às diretrizes que definem sua identidade. Essa questão implica perguntar-se sobre quem o realiza, o espaço em que ele se realiza e suas relações com o meio sociocultural. Enquanto a primeira avaliação aceita uma dada educação e procura saber seus efeitos sobre as crianças, a segunda interroga a oferta que é feita às crianças, 
confrontando-a com parâmetros e indicadores de qualidade. Essa é feita por um conjunto de profissionais do sistema de ensino (gestores, diretores, orientadores pedagógicos e outros especialistas, professores), pelos pais, dirigentes de organizações da comunidade etc. (Brasil, 2012, p. 13)

Desse modo, a avaliação da qualidade na educação infantil refere-se a aprendizagem da criança e a avaliação da educação infantil está relacionada a avaliação dos serviços prestados pela unidade educativa. Dependendo de sua abrangência a avaliação da educação infantil classifica-se em larga escala, se estiver mapeando uma rede de ensino, região, estado, em âmbito nacional. Nesta especificidade, a avaliação pode apresentar a metodologia de coleta de dados da população, tanto por amostragem, quanto censitária. É importante considerar que as escolhas definem as estratégias e os elementos constitutivos do instrumento nos espaços institucionais que atendem crianças de pouca idade.

O conceito de avaliação apresenta diferentes abordagens, mas Bondioli e Savio (2015) definem o conceito de modo amplo e subjetivo simultaneamente, de valoração da qualidade, numa perspectiva participativa e em consonância com o que a referida pesquisa trata:

No que diz respeito à avaliação, segundo a definição clássica, a evaluation determina o valor de um objeto qualquer (evaluandum), exige uma coleta sistemática de informações sobre a realidade a ser avaliada, implica a atribuição de um juízo com base em critérios transparentes, tem uma finalidade pragmática, orientada a tomada de decisão, à ação futura, à melhoria do existente [...] avaliação como um processo democrático que promova a inclusão, o diálogo, a deliberação, o empowerment profissional. (p. 24)

A metodologia utilizada para o levantamento de dados numa avaliação torna-se basilar para algumas definições como, por exemplo: possibilita a identificação da concepção pedagógica do instrumento; por meio do levantamento de dados sistematizados tem a capacidade de mapear o nível de qualidade da oferta dos serviços da unidade educativa - creche e pré-escola -; atende a finalidade democrática quando promove uma dinâmica participativa e deliberativa dos diferentes segmentos da instituição.

\section{Descrição dos elementos a serem considerados em um modelo de avaliação}

Com o objetivo de subsidiar a elaboração de um sistema nacional de avaliação da educação infantil, contribuir técnica e pedagogicamente com os municípios brasileiros, o documento intitulado Educação infantil: subsídios para a construção de uma sistemática de avaliação (Brasil, 2012), elaborado pelo grupo de trabalho instituído pela portaria $\mathrm{n}$. 1.147/2011, aborda alguns parâmetros e critérios que devem constar no instrumento avaliativo. Esses parâmetros baseiam-se nas concepções de criança como centro do planejamento curricular, infância e educação infantil.

O documento pressupõe que a avaliação deve basear-se num conjunto de indicadores relativos ao acesso, insumos e processos, considerando as especificidades institucionais. O acesso refere-se as condições de oferta da educação infantil em espaços institucionais abrangendo desde o financiamento, a estrutura, a garantia dos sujeitos e o 
serviço de apoio; os insumos são as condições e fatores presentes na legislação que normatizam a condição de uma oferta de qualidade; os processos referem-se à gestão, ao currículo e às relações e interações presentes na instituição (Brasil, 2012, p.23).

Desse modo os instrumentos de avaliação da qualidade da educação infantil devem levantar dados sobre o ambiente físico, relacional e social. Também existem modelos que enfatizam as práticas pedagógicas e a relação com a comunidade educativa.

Um instrumento de avaliação da educação infantil deve passar por um processo de validação e confiabilidade do constructo; o instrumento deve ter a capacidade de medir a que se propõe; a metodologia de coleta de dados deve basear-se na avaliação de ambientes, insumos e processos; apresentar nos indicadores o padrão de qualidade que atenda os princípios da educação infantil; considerar a diversidade contextual; possibilitar a participação dos diferentes segmentos da comunidade educativa; propor e acompanhar melhorias a partir dos resultados.

É previsível que cada instrumento avaliativo apresente pontos fortes e fracos. Mas quanto mais alinhado aos parâmetros e critérios de qualidade estabelecidos em determinada rede de ensino ou instituição, maior a possibilidade de confiabilidade ao mensurar a qualidade dos serviços da educação infantil. Assim, foram elencados os elementos que os identificam e possibilitam comparar os instrumentos, considerando o objetivo e a metodologia de cada modelo de avaliação.

a) Tipo de avaliação: classifica-se autoavaliação, metaavaliação, heteroavaliação ${ }^{5}$, um instrumento pode apresentar um ou combinar dois ou mais tipos;

b) a metodologia: a estratégia de coleta de dados sobre os sujeitos ou ambientes avaliados, realizada por avaliador externo ou por avaliadores externos e internos; as estratégias adotadas em cada etapa da avaliação;

c) tempo: período destinado a observação e coleta de dados;

d) os indicadores: aspectos a serem mensurados;

e) participação: promove a reflexão dos diferentes segmentos (profissionais e famílias) sobre experiências pedagógicas e seus valores educativos, consolidando a identidade da instituição e legitimando o processo avaliativo.

f) resultados: relacionado ao objetivo, se contempla os aspectos indicados ou não;

g) pós-resultados: são os encaminhamentos posteriores ao resultado;

h) viabilidade: se o instrumento se encontra em consonância ou não com a proposta pedagógica, gera custos e tem a necessidade de profissionais especializados;

i) confiabilidade: refere-se ao nível de maturação do instrumento, quantas vezes foi aplicado, em qual contexto e se mensurou o nível de qualidade.

${ }^{5}$ Autoavaliação: Quando a instituição faz uma avaliação interna a partir de indicadores e itens previstos em um instrumento avaliativo. Metaavaliação: o objetivo fazer uma avaliação da avaliação, quando a instituição parte do resultado e com base nos seus valores e finalidades, faz as melhorias que considera necessária, de modo a comprovar a qualidade da avaliação. Heteroavaliação: avaliação de outrem feita por uma ou mais pessoas ou entidades que não estão sendo avaliadas neste momento, mas que também refletem sobre sua própria realidade e tem como objetivo a promoção de dinâmicas reflexivas no grupo de trabalho, o qual tem então a possibilidade real de decidir sobre o que e como intervir (Gariboldi, Mazelli, 2018, p. 59.) 
Figura 1 -

Elementos a serem caracterizados na comparação de um instrumento de avaliação qualidade da educação infantil.

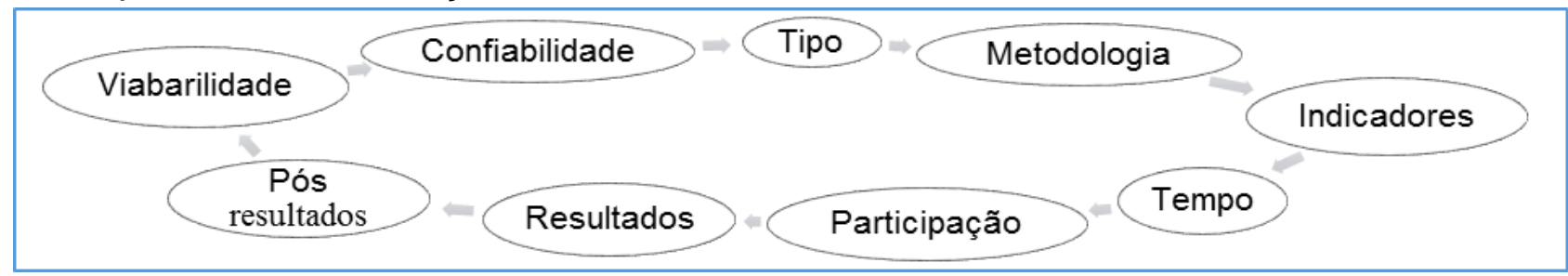

Fonte: autora.

Neste artigo são analisados em maior detalhe dois modelos de avaliação da educação infantil já aplicados na rede municipal de ensino de Florianópolis/SC. Ambos os modelos de avaliação foram baseados nos ambientes, insumos e processos, sendo destinados a faixas etárias para crianças de creche e pré-escola. Partindo das informações descritas em cada modelo e na análise dos mesmos ao longo dos critérios estabelecidos, pretende-se verificar a pertinência dos mesmos para a avaliação da qualidade da educação infantil do município de Florianópolis/SC.

\section{Comparação entre os instrumentos de avaliação utilizados em Florianópolis/SC}

Os modelos de avaliação utilizados para aferir a qualidade dos serviços no município de Florianópolis/SC são de origem estrangeira. As escalas norte americanas Iters-R e Ecers-R (Harms; Clifford; Cryer, 2004, 1998) avaliam os espaços e ambientes: espaços e materiais. Em 2009 o estudo intitulado A qualidade da educação infantil: um estudo em seis capitais brasileiras (Campos et al., 2011), foi realizado em Belém, Campo Grande, Fortaleza, Rio de Janeiro, Florianópolis/SC e Teresina. As cidades supracitadas, concomitantemente, passaram por um processo de avaliação por amostragem em que participaram 147 instituições de educação infantil. Entre as unidades avaliadas 30 instituições pertenciam ao município de Florianópolis/SC.

Em 2015 o município de Florianópolis/SC passou por um novo processo de avaliação da qualidade dos ambientes financiada pelo Banco Interamericano de Desenvolvimento. Para melhorar a qualidade e expandir a cobertura educacional a Prefeitura Municipal de Florianópolis/SC elaborou o Projeto de ampliação e melhoria da educação básica"6, coordenado pela Fundação Carlos Chagas, utilizando os mesmos modelos avaliativos - Iters- $R$ e Ecers- $R$-, no entanto, de forma censitária, realizadas nas 87 unidades educativas municipais de educação infantil, com réplica prevista para 2019. Foi a primeira avaliação da educação infantil de mapeamento da qualidade em larga escala desde sua oferta, iniciada em 1976.

Já os instrumentos avaliativos italianos Isquen (Becchi; Bondioli; Ferrari, 1999) e AVSI (Bondioli; Ferrari, 2008), baseiam-se na avaliação de contexto. Coutinho, Barbosa e

6 O Programa foi financiado por um empréstimo aprovado em novembro de 2013 de US\$ 59 milhões com o prazo de 25 anos e um período de carência de cinco anos e meio. A taxa de juros foi baseada nas taxas de juros do banco Iondrino London Interbank Offered Rate - Libor. Tornou-se o primeiro financiamento internacional no território brasileiro com valor investido integralmente em educação (Florianópolis/SC, 2013). 
Moro (2015), em parceria com pesquisadoras italianas da Universidade de Pávia, coordenaram um estudo para o debate sobre a potencialidade avaliativa do instrumento em quatro capitais brasileiras: Curitiba, Belo Horizonte, Florianópolis e Rio de Janeiro em quatro unidades de educação infantil, uma instituição de cada rede municipal de ensino em questão.

Os modelos de avaliação utilizados apresentam características distintas, principalmente no que se refere à metodologia, à participação da comunidade educativa, à formação docente e ao processo de continuidade nos resultados posteriores que interferem na melhoria da qualidade do atendimento a longo prazo. No quadro 3 apresenta-se o comparativo entre os dois modelos de avaliação aplicados nas instituições de educação infantil da rede municipal de ensino de Florianópolis/SC.

Quadro 3 -

Levantamento das informações dos instrumentos de avaliação da educação infantil aplicados na rede municipal de ensino de Florianópolis/SC ao longo dos nove elementos definidos.

\begin{tabular}{|c|c|c|c|c|}
\hline Elementos & \multicolumn{2}{|c|}{$\begin{array}{c}\text { Modelo } 1 \text { - Iters-R/Ecers-R } \\
\text { (Avaliação de Espaços e Ambientes) }\end{array}$} & \multicolumn{2}{|c|}{$\begin{array}{c}\text { Modelo } 2 \text { - Isquen/AVSI (Avaliação de } \\
\text { Contexto) }\end{array}$} \\
\hline ipo & \multicolumn{2}{|c|}{ Avaliação externa } & \multicolumn{2}{|c|}{ Metaavaliação e Autoavaliação. } \\
\hline Metodologia & \multicolumn{2}{|c|}{$\begin{array}{l}\text { Um avaliador externo observa, } \\
\text { identifica e atribui conceito de } \\
\text { qualidade, por meio de indicadores } \\
\text { relacionados aos espaços e } \\
\text { materiais propostos: se possibilitam } \\
\text { o acesso as crianças, estão em } \\
\text { quantidade suficiente, são } \\
\text { adequados a faixa etária e } \\
\text { possibilitam escolhas. }\end{array}$} & \multicolumn{2}{|c|}{$\begin{array}{l}\text { Constituído por um avaliador externo, } \\
\text { avaliadores internos (entre eles, um } \\
\text { articulador) e outros segmentos da } \\
\text { instituição como famílias } \\
\text { profissionais que atuam diretamente } \\
\text { com as crianças. Apresenta } \\
\text { indicadores pré-definidos, mas o } \\
\text { objetivo maior é promover o debate } \\
\text { entre os participantes. }\end{array}$} \\
\hline Indica & $\begin{array}{l}\text { Iters-R } \\
\text { (creche): } \\
\text { espaço e } \\
\text { mobiliário; } \\
\text { rotinas de } \\
\text { cuidado } \\
\text { pessoal; falar e } \\
\text { compreender; } \\
\text { atividades; } \\
\text { interação; } \\
\text { estrutura do } \\
\text { programa, pais } \\
\text { e equipe. }\end{array}$ & $\begin{array}{l}\text { Ecers-R (pré- } \\
\text { escola) } \\
\text { espaço e } \\
\text { mobiliário; rotinas } \\
\text { de cuidado } \\
\text { pessoal, } \\
\text { linguagem e } \\
\text { raciocínio; } \\
\text { atividades; } \\
\text { interação, } \\
\text { estrutura do } \\
\text { programa e; pais e } \\
\text { equipe. }\end{array}$ & $\begin{array}{l}\text { Isquen (creche): } \\
\text { os sujeitos; os } \\
\text { contextos e } \\
\text { práticas; os } \\
\text { saberes do fazer; } \\
\text { as garantias. }\end{array}$ & \begin{tabular}{|l|} 
AVSI \\
(pré-escola) \\
experiência \\
educativa; as \\
atividades \\
profissionais; os \\
adultos e as suas \\
relações; as \\
garantias; a \\
estrutura.
\end{tabular} \\
\hline $\begin{array}{l}\text { Tempo } \\
\text { aplicação }\end{array}$ & \multicolumn{2}{|c|}{$\begin{array}{l}\text { Um dia, período de } 3,5 \text { horas de } \\
\text { observação do avaliador externo ao } \\
\text { espaço-tempo } \\
\text { selecionado. }\end{array}$} & \multicolumn{2}{|c|}{$\begin{array}{l}\text { Varia de uma instituição para outra. } \\
\text { Não descreve o tempo de aplicação } \\
\text { do instrumento. A avaliação é } \\
\text { realizada por etapas, processual, } \\
\text { prevê vários encontros com objetivos } \\
\text { distintos, inclusive com a formação } \\
\text { dos participantes, qualificando-os. }\end{array}$} \\
\hline Partic & \multicolumn{2}{|c|}{$\begin{array}{l}\text { A partir dos dados levantados } 0 \\
\text { avaliador externo conduz e se torna } \\
\text { o único a aferir o nível de qualidade. }\end{array}$} & \multicolumn{2}{|c|}{$\begin{array}{l}\text { De natureza negociada e dialógica } \\
\text { prevê a participação de todos os } \\
\text { segmentos. }\end{array}$} \\
\hline esult & \multicolumn{2}{|c|}{$\begin{array}{l}\text { Os dados e informações sobre a } \\
\text { qualidade } \\
\text { são } \\
\text { coletados, }\end{array}$} & \multicolumn{2}{|c|}{$\begin{array}{l}\text { Os itens } \\
\text { discordância, são socializados a fim }\end{array}$} \\
\hline
\end{tabular}




\begin{tabular}{|c|c|c|}
\hline & $\begin{array}{l}\text { mensurados e divulgados pelo } \\
\text { avaliador externo que também } \\
\text { atribui o juízo de valor. }\end{array}$ & $\begin{array}{l}\text { de refletir e encontrar o consenso a } \\
\text { partir da concepção, dos valores } \\
\text { daquela realidade e dos princípios da } \\
\text { educação infantil. }\end{array}$ \\
\hline Pós resultados & $\begin{array}{l}\text { O avaliador externo faz os } \\
\text { indicativos sobre pontos a serem } \\
\text { melhorados e estratégias de ação, } \\
\text { como por exemplo, a formação } \\
\text { continuada dos profissionais. }\end{array}$ & $\begin{array}{l}\text { Elaboração de um plano de ação } \\
\text { coletivo, tornando-os coadjuvantes } \\
\text { das melhorias. }\end{array}$ \\
\hline Viabilidade & $\begin{array}{l}\text { Demanda menor custo financeiro } \\
\text { pela facilidade de acesso e pouco } \\
\text { tempo na preparação dos } \\
\text { avaliadores externos. }\end{array}$ & $\begin{array}{l}\text { Demanda investimento financeiro } \\
\text { maior, por ser processual, pela } \\
\text { necessidade de interação do avaliador } \\
\text { externo que é o articulador do } \\
\text { instrumento: requer maior qualificação } \\
\text { conforme as etapas avancam. }\end{array}$ \\
\hline Confiabilidade & $\begin{array}{l}\text { Grau de maturidade estabelecido, } \\
\text { porque foi aplicado em diferentes } \\
\text { contextos e tempos históricos. }\end{array}$ & $\begin{array}{l}\text { Grau de maturidade estabelecido, } \\
\text { também aplicado em outros países. } \\
\text { No entanto, por avaliar o contexto, } \\
\text { necessita de adaptação à realidade } \\
\text { observada. }\end{array}$ \\
\hline Considerações & $\begin{array}{l}\text { Abrangente no mapeamento da } \\
\text { qualidade: ao aplicar na RME de } \\
\text { Florianópolis/SC não previu a } \\
\text { participação da comunidade escolar. } \\
\text { Abriu precedente em relação a } \\
\text { participação dos sujeitos/segmentos } \\
\text { da instituição, direcionando } \\
\text { responsabilização pelos resultados. }\end{array}$ & $\begin{array}{l}\text { Trata-se da avaliação de contexto: } \\
\text { prioriza a participação ao mobilizar e } \\
\text { empoderar os sujeitos. Demanda } \\
\text { recursos e a criação da cultura de } \\
\text { comprometimento/ responsividade } \\
\text { sobre a qualidade do atendimento. }\end{array}$ \\
\hline
\end{tabular}

Fonte: autora.

No modelo avaliativo 1 - Iters-R/Ecers-R - avaliação de ambientes para creche e pré-escola - a avaliação foi realizada no município de Florianópolis/SC tanto por amostragem, quanto de maneira censitária. Tem a característica de ser realizada por avaliadores externos, não requer a participação dos profissionais, que tiveram acesso apenas sobre os itens e indicadores avaliados. Os dados são obtidos a partir da observação sobre a disposição de elementos presentes ou não nos ambientes. Somente quando os objetos não são visualizados os profissionais da instituição são consultados pelo avaliador externo, ou seja, propõe uma participação passiva. A proposição de melhorias também é orientada pelo avaliador externo a partir das informações coletadas. Neste sentido direciona a responsabilização de quem presta os serviços pelos resultados, sem considerar as condições estruturais.

No modelo de avaliação 2 - Isquen/AVSI - a avaliação foi realizada por amostragem numa instituição e com metodologia de autoavaliação e metaavaliação. $O$ instrumento precisa ser adaptado ao contexto, demanda um trabalho articulado, em que todos os segmentos da instituição participam. Tal metodologia requer comprometimento, responsabilidade, conhecimento dos participantes e abertura para o processo avaliativo, tomando os resultados como uma necessidade de aprimoramento das práticas pedagógicas, no sentido de manter e, se necessário, melhorar sua atuação profissional. $\mathrm{O}$ 
processo formativo que a avaliação pressupõe requer autorreflexão e identificação dos pontos fortes e fracos da instituição, bem como criticidade em torno das escolhas para a construção de um plano de ação e o acompanhamento do mesmo como um compromisso coletivo e articulado entre os diferentes segmentos institucionais.

Tanto o modelo de avaliação 1 quanto 02 necessitaram de adaptação à realidade da rede municipal de ensino de Florianópolis/SC. O modelo 2 apresenta maior número de requisitos em consonância com a proposta pedagógica da educação infantil municipal, assim como as possibilidades de participação, formação, atender as especificidades regionais de um município composto por 89 escolas distintas entre si. Também numa avaliação de contexto evidencia-se a necessidade de assegurar estrutura física, material e humana, além do investimento na qualificação dos avaliadores externos que desempenham um importante papel de mediação na efetivação da avaliação.

\section{Considerações finais}

A avaliação institucional da qualidade da educação infantil deve basear-se na compilação de informações sobre diferentes aspectos, considerando as especificidades próprias desse nível educacional. Entre eles destacam-se: a formação de professores; a estrutura da instituição; o currículo; as práticas pedagógicas; as políticas voltadas à primeira infância; o trabalho pedagógico com a oferta de tempos, espaços e materialidades que promovam uma estimulação para a ampliação de repertórios, ou seja, a referida prática pedagógica deve propiciar as condições para a aprendizagem (Brasil, 2012).

Este trabalho se propôs a analisar as características essenciais que devem compor um instrumento de avaliação. Com o levantamento bibliográfico referente aos modelos de avaliação da qualidade da educação infantil foi possível conhecer os aspectos comuns relacionados às implicações políticas e metodológicas dos modelos. Conforme observado os modelos de avaliação definem um conceito de padrão de qualidade atribuindo um nível a partir do levantamento de dados; perpassam por concepções de educação, criança, infância e sociedade, ou seja, a partir da realidade observada constam elementos que representam a concepção de educação idealizada; baseiam-se num método e concepção pedagógica, a metodologia da avaliação prevê a participação da comunidade educativa; refletem as características dos sistemas de ensino; estão atrelados ao financiamento da educação infantil que define metas a serem alcançadas a partir do investimento no sistema de ensino; retroalimentam as políticas públicas para a infância, possibilitando que as inovações e melhorias sejam implementadas a partir do mapeamento da avaliação. 
Figura 2 -

Implicações políticas e metodológicas dos modelos de avaliação da qualidade da educação infantil.

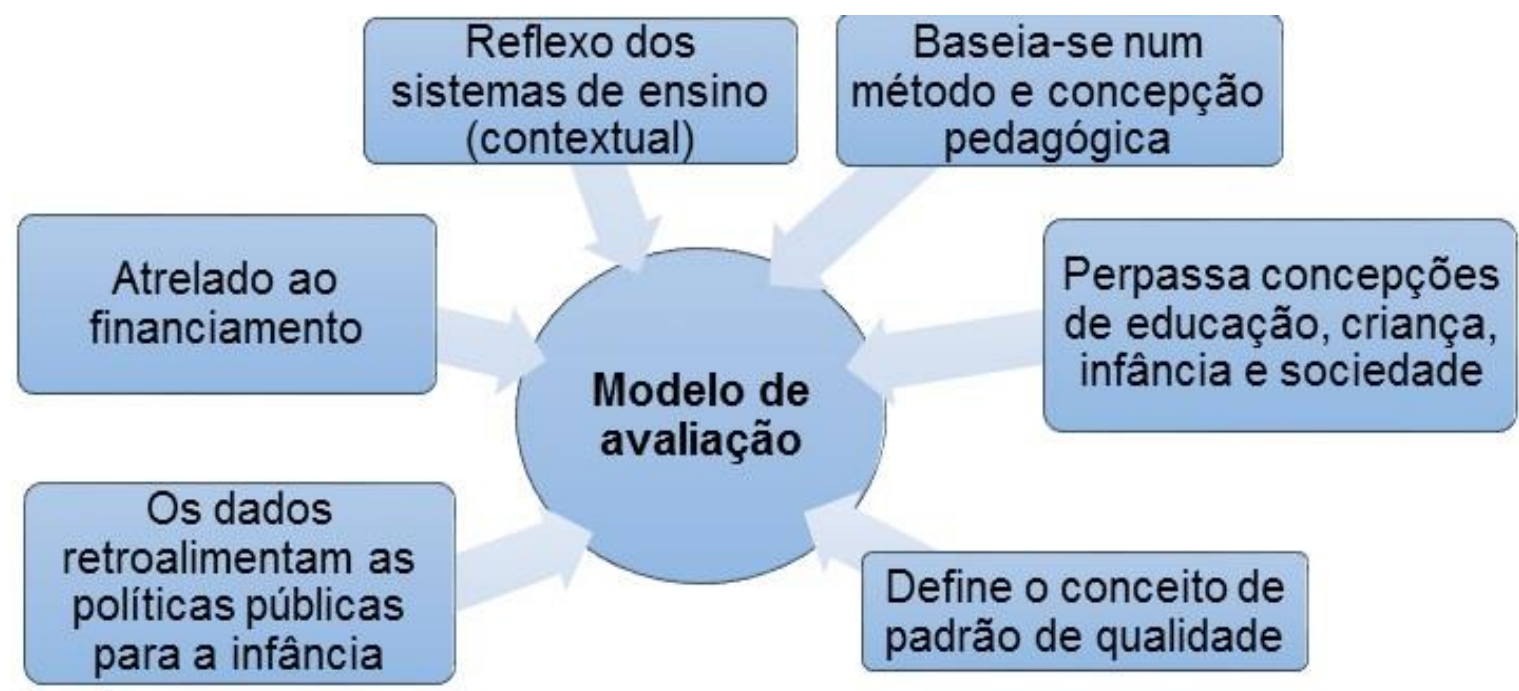

Fonte: autora.

Como foi possível observar, um modelo de avaliação apresenta inúmeras implicações, pois são constituídos por um conjunto de fatores próprios de cada sistema de ensino e das políticas públicas para a infância. Em muitos países, como Estados Unidos, Itália, Austrália, já estão consolidados. No México, por exemplo, foi necessário um tempo maior no processo de implementação e adequação do instrumento para atender aos objetivos educacionais.

O Brasil também criou seu próprio modelo de avaliação - Indicadores da qualidade da educação infantil (2009) baseado nos critérios e parâmetros nacionais da qualidade e, posteriormente, o município de São Paulo adaptou à sua proposta pedagógica. No entanto, em se tratando dos indicadores do MEC não obteve-se êxito na adesão da avaliação e a descontinuidade das políticas educacionais tem dificultado a implantação de uma avaliação de abordagem sistêmica, intersetorial e articulada à política pública em torno da oferta de um atendimento de qualidade na educação infantil.

$\mathrm{Na}$ presente pesquisa, foram analisados os dois modelos de avaliação aplicados na rede da capital catarinense, buscando identificar a adequação dos mesmos à realidade da educação infantil de Florianópolis/SC. A análise destes modelos mostrou que o instrumento avaliativo deve ser contextual, basear-se numa concepção metodológica em consonância com a proposta pedagógica da educação infantil municipal assim como prever a participação da comunidade educativa, a formação continuada, atender as especificidades regionais e considerar a identidade das unidades educativas em um município composto por 89 escolas públicas.

De modo geral, a avaliação da qualidade precisa ter natureza científica, com rigor técnico e procedimentos legitimados para identificar se a instituição atende ou não sua finalidade e diretrizes. Para além das informações previstas no modelo avaliativo de coleta de dados, o resultado deve ser a compilação do cruzamento de dados formais 
como censo escolar, demais programas e o financiamento educacional que fomentam o acesso, a infraestrutura, os recursos materiais, a formação de professores, gestão dos sistemas e das instituições.

\section{Referências}

AKVILE, Motiejunaite (coord.). Eurydice resumen ejecutivo: la educación y atención a la primera infancia. 2014 Luxemburgo: União Européia. Disponível: https://publications.europa.eu/en/publication-detail/-/publication/25c63f11-c2cb-4c4c-a3cb85d9b1eab93b/language-en/format-PDF/source-search. Acesso em 1ํ jun. 2019.

AUSTRALIAN CHILDREN'S EDUCATION AND CARE QUALITY AUTHORITY. Guide to the national quality framework. Sydney: Acecqa, 2018.

BONDIOLI, Anna. Indicadores operativos e análise da qualidade: razões e modos de avaliar In: CIPOLLONE, Laura (org.). Instrumentos e Indicadores para avaliar a creche: um percurso de análise da qualidade. Curitiba: UFPR, 2014, p. 47-72.

BONDIOLI, Anna; SAVIO, Donatella. Elaborar indicadores da qualidade educativa das instituições de educação infantil: uma pesquisa compartilhada entre Itália e Brasil. In: SOUZA, Gizele de; MORO, Catarina; COUTINHO, Angela Scalabrin (orgs.). Formação da rede em educação infantil: avaliação de contexto. Curitiba: Appris, 2015, p. 21-49.

BRASIL. Contribuições para a política nacional: avaliação em educação infantil a partir da avaliação de contexto. Brasília: MEC, 2015.

BRASIL. Indicadores da qualidade na educação infantil. Brasília: MEC/SEB, 2009.

BRASIL. Educação infantil: subsídios para a construção de uma sistemática de avaliação. Brasília: MEC, 2012.

BRASIL. Lei de diretrizes e bases da educação nacional. Brasília: MEC, 1996.

BRASIL. Plano nacional de educação. Brasília: MEC, 2014.

BRASIL. Sistema nacional de avaliação da educação básica. http://portal.inep.gov.br/educacao-basica/saeb. Acesso em 16 nov. 2019.

CAMPOS, Maria Malta; ESPOSITO, Yara Lúcia; BHERING, Eliana; GIMENES, Nelson; ABUCHAIM, Beatriz. A qualidade da educação infantil: um estudo em seis capitais brasileiras. Cadernos de Pesquisa, v. 41 n. 142, 2011, p. 20-54.

COUTINHO, Angela Scalabrin; MORO, Catarina; SOUZA Gizele de. A pesquisa em rede: marcas do percurso acerca da avaliação de contexto em educação infantil. In: SOUZA Gizele de; MORO, Catarina; COUTINHO, Angela Scalabrin (orgs.). Formação da rede em educação infantil: avaliação de contexto. Curitiba: Appris, 2015, p. 51-71.

COR. Estados Unidos. Disponível em: https://highscope.org/our-practice/our-approach/. Acesso em 21 nov. 2019.

FIORAVANTI-BASTOS, Ana Carolina Monnerat; FILGUEIRAS, Alberto; MOURA, Maria Lucia Seidl de. Avaliação do ages and stages questionnaire Brasil por profissionais de educação infantil. Estudos de Psicologia, Campinas, v. 33, 2016, p. 293-301.

FLORIANÓPOLIS/SC. BID aprova $R \$ 130$ mi para educação na capital. Florianópolis/SC: Prefeitura $\quad$ Municipal, $2013 . \quad$ Disponível em http://www.pmf.sc.gov.br/mobile/index.php?pagina=notpagina\&noti=10685. Acesso em 17 nov. 2019. 
GREAT BRITAIN. Early years foundation stage: profile handbook. London: Qualifications and Curriculum Authority, 2008.

HARMS, Thelma. O uso de escalas de avaliação de ambientes na educação infantil. Cadernos de Pesquisa, São Paulo, v. 43 n. 148, 2013, p.76-97.

HARMS, Thelma; CRYER, Debby; CLIFFORD, Richard M. Infant/toddler environment rating scale: revised edition. New York: Teachers College Press, 2006.

MARCUCCIO, Massimo; ZANELLI, Paolo (a cura di). Sguardi sul nido: strumento per lo Sviluppo di Processi Riflessivi e Indagini valutative nei Nidi da parte dei Gruppi di lavoro educativi. Parma: Junior-Spaggiari, 2013.

MORO, Catarina. Diferentes olhares para a creche: a avaliação de contexto com o instrumento Spring num município da Emilia Romagna. Revista Linhas, Florianópolis/SC, v. 19 , n. 40,2018 , p. 138-160.

MYERS, Robert. Em busca da qualidade educacional na pré-escola: uma experiência mexicana. Cadernos de Pesquisa, São Paulo, v. 41, n. 142, 2011, p.100-115.

PIMENTA, Cláudia Oliveira. Avaliações municipais da educação infantil: contribuições para a garantia do direito à educação das crianças brasileiras? São Paulo: USP, 2017. 668f. Tese (doutorado em Educação). Universidade de São Paulo, Faculdade de Educação.

PRECIADO, José Francisco Martínez. La construcción de indicadores y evaluación de la calidad en centros educativos: seis experiencias en México. Reice - Revista Iberoamericana sobre Calidad, Eficacia y Cambio en Educación, Madrid, v. 8, n. 5, 2010, p. 133-153.

IETS. Manual de uso do ASQ-3: guia rápido para aplicação do ASQ-3. Rio de Janeiro: Instituto de Estudos do Trabalho e Sociedade, 2010.

SÃO PAULO. Indicadores de qualidade da educação infantil paulistana. São Paulo: Secretaria Municipal de Educação, 2016.

SOUSA, Sandra Maria Zákia Lian; PIMENTA, Cláudia Oliveira. Avaliação e gestão da educação infantil em municípios brasileiros. Educação \& Realidade, Porto Alegre, v. 43, n. 4, 2018, p. 1277-1300.

SOUSA, Sandra Maria Zákia Lian; PIMENTA, Cláudia Oliveira. Avaliação da educação infantil: aportes de iniciativas estrangeiras. Est. Aval. Educ., São Paulo, v. 27, n. 65, 2016, p. 376-406.

SOUZA, Gizele de; MORO, Catarina; FRANÇA, Franciele Ferreira; RODRIGUES, Ana Julia Lucht. A pesquisa em rede na educação infantil: avaliação de contexto, modos de proceder e possibilidades de reflexão. Evaluación de contextos en Educación Infantil, Santiago de Compostela, 2017, p. 23-32.

TAYLER, Collette. Avaliação da qualidade da educação infantil na Austrália. Estudos em Avaliação Educacional, São Paulo, v. 25, n. 58, 2014, p. 126-151.

Dirce Guerres Zucco é estudante no curso de Mestrado no Programa de PósGraduação em Métodos e Gestão em Avaliação da Universidade Federal de Santa Catarina.

Orcid: https://orcid.org/0000-0001-6547-9866.

Endereço: Rua Henrique Alvim Correia, 630 - 88113-830 - São José - SC - Brasil.

E-mail: dirceguerreszucco@gmail.com. 
Andreia Zanella é professora na Universidade Federal de Santa Catarina.

Orcid: http://orcid.org/0000-0002-0651-0349.

Endereço: Rua Delfino Conti, s/n - UFSC-INE - 88040-370 - Florianópolis - SC Brasil.

E-mail: andreia.zanella@ufsc.br.

Patrícia de Sá Freire é professora na Universidade Federal de Santa Catarina.

Orcid: https://orcid.org/0000-0002-9259-682X.

Endereço: Rua Delfino Conti, s/n - UFSC-INE - 88040-370 - Florianópolis - SC Brasil.

E-mail: patricia.sa.freire@ufsc.br.

Recebido em 28 de novembro de 2019.

Aceito em 3 de janeiro de 2020.

(c) (i) 